\title{
2020 National High School Big Data Challenge: New Climate and Information Realities - From Oceans to Glass of Water
}

\author{
Youth Leading Sustainability Innovation through Big Data
}

Under the patronage of Canadian Commission for UNESCO

STEM Fellowship's Big Data Challenge is a unique pedagogical experiment, providing an inquiry and learning experience for high school students that, upon equipping them with top-notch analytical tools, tasks them to find hidden patterns and trends in complex scientific data. This year's challenge provided a multidisciplinary competitive opportunity; over a period of three months, teams analysed sustainability data through the prism of computational methods. Teams worked to reveal the impact of environmental conditions on human health and well-being, diving into predictive analytics of the global and micro-climate change impacts of water and oceans on communities, energy generation, agriculture, entrepreneurship, and more.

The tools used by teams were similarly diverse, ranging from $\mathrm{R}$ and Python to SAS Studio and Tableau. For all the variation between project themes, it remains that all submissions are of incredibly high quality. Every paper is demonstrative of immense creativity and high potential on the respective team's part.

On behalf of STEM Fellowship, I would like to extend my heartfelt congratulations to all students who participated in the Challenge, and I wish them all the best for their future endeavours in research and data science. It has been a privilege for us to witness the analytical capabilities of the next generation of students firsthand, and I am certain all entrants will continue to demonstrate excellence in their respective research careers.

\section{Elena Pan}

Director for Data Science Education

STEM Fellowship Big Data Challenge 2019-2020
Dr. Sacha Noukhovitch

Founder, President and Editor-in-Chief

STEM Fellowship/STEM Fellowship Journal

\section{Disclaimer}

These abstracts are provided for all student teams that have submitted project reports by January 26, 2020. The STEM Fellowship Journal editorial board has made every effort to ensure proof and English editing of these abstracts in a limited amount of time, and neither organization as a whole or any of its volunteer members can be held accountable for inaccuracies that may have occurred in the abstract publication. 


\section{An Investigation of the Association Pattern Between Climate and Waterborne Disease Cases}

\section{Michael Yang}

\section{Bloor Collegiate Institute}

Each year, over 3.4 million deaths occur due to waterborne diseases making it the leading cause of death in the world. As atmospheric and water temperatures are gradually on the rise, setting new records, more cases of waterborne diseases such as Cholera, Cryptosporidium, and other waterborne pathogens have been reported. Despite the evidence of increasing cases of waterborne diseases, little is known about the relationship between waterborne disease and climate change. In this paper, I explored this relationship using data on health and disease from: (i) the World Health Organization (WHO), (ii) Centre for Disease Control and Prevention (CDC), and data on temperature and precipitation from (iii) Statistics Canada, and (iv) the National Oceanic and Atmospheric Administration (NOAA).

Descriptive analysis showed an association between waterborne diseases and precipitation. Trend analysis of extreme precipitation data (1910 to 2012) indicated the occurrence of extreme precipitation had been increasing over the years from $14 \%$ to $26 \%$ and peaked at $34 \%$ in 1983 . Additionally, the number of patient hospitalizations, illnesses, and deaths associated with waterborne pathogens had steadily increased over the past 10 years. The findings also showed that reported cases in the winter were significantly less than during the summer months. A feasible explanation is that warmer water temperature can create a conducive environment for waterborne pathogens to replicate and be transmitted.

Based on my findings and the fact that there was a steady increase in global temperature, it was likely that waterborne diseases could potentially become prevalent throughout the year. I advocate for immediate actions to reduce greenhouse gas emissions so as to lessen the impact of increasing water temperature.

This small study was not able to establish with certainty that climate is a major causal factor for the increasing number of waterborne disease cases. More research can be conducted on the epidemiology of infectious diseases to find ways to mitigate their impact on human lives.

\section{How Water Temperature Affect the Characteristics of Fish Species Caught in Atlantic Canada}

\section{Eric Chen, Joshua Scripcaru, Justin Pang, Leo Tao}

Earl Haig Secondary School

This paper examines how the temperature of water affects fish caught in the Maritime region.

Utilizing data from freshwater and saltwater ecosystems in Atlantic Canada, the correlation between abundance, weight, size of fish with the temperature of the water was investigated. Our analysis was performed using Excel and SAS.

Following the analysis, a variety of different correlations between the previously mentioned data were found in both freshwater and saltwater environments.

The report focuses on the most popular common fish species - Atlantic Salmon, American Eels, Brook Trout and Rainbow Smelt - and a strong parabolic correlation was found in American Eels and Rainbow Smelt.

It is observed that global warming did have a significant role in species with large life spans, however no trend was discovered in those with short life spans. The paper proceeds to examine the validity, significance and impact of our findings and how changing temperatures will affect the marine environment.

\section{Correlation between Water Quality and the Emotion of a Population}

Arya Shababi, Ali Seena Shakeri, Robin Nash, Maria Pasychnyk

\section{Earl Haig Secondary School}

The purpose of this study is to examine the effects that water filtration can have on the mood of a population. In order to examine these effects, set locations were analyzed by the percentage of households within the said locations that filtered their drinking water. This was compared with the "mood" of posts from the set locations. The posts came in the form of tweets from the social media platform 
Twitter. This data was gathered and analyzed using tools like Microsoft Excel, Python 3.7, Bash, and the AFINN Lexicon. The tool twitterscraper was used to extract tweets from Twitter using custom queries. In all, data was gathered from 33 cities across Canada, ranging from coastal to inland cities, across 8 provinces. The initial hypothesis was that in cities with more households that filter their drinking water, the mood of the city's population would be more positive. This was backed up by results. A positive linear relation between the two was found in general tweets with an unspecified topic, and with water related tweets. In this report the potential reasons for this correlation are explored. Such reasons include the effect of unfiltered water on mental health, the physical effects that unfiltered water has on the human body, and the possibility of a reverse causation. The research in this study has lead to the conclusion that dwellings with adequate filtering house happier people. This is a concern for populations without proper access to clean drinking water, as the mental health of these populations will deteriorate over time.

\section{The Effects of War on the Environment, Economy, and Mental Health}

\section{Arash Motazedian, Armin Motazedian, Sepehr Safa, Mehrdad Ghannad}

\section{Earl Haig Secondary School}

It is a sad fact that millions of people in different regions of the world feel the threat of war every second of their lives. Wars claim the lives of many innocent people and the world currently feels the threat of another war. The purpose of this research is to outline the sad realities of war and conflict by using statistical measures. This research further studies the consequences of war by analyzing how war affects the environment, the economy, and people's mental health. Countries such as Iraq, Syria, and Afghanistan which have been devastated by war were carefully studied in this research. To understand the effects of war on the environment, data related to $\mathrm{CO} 2$ emission and air pollution levels was collected. Data was also collected regarding GDP per capitas and unemployment rates of the countries named above. In addition, suicide rates were also analyzed to study the effects of war on mental health. Graphs were developed in order to aid with the analysis and possibly visualize significant trends or patterns. Our analysis proved that in countries at war, the environment is greatly in danger due to a dramatic rise in $\mathrm{CO} 2$ and air pollution levels, which subsequently affect people's health. Furthermore, a correlation was observed between levels of military tensions and economic turmoil where as a result of war, unemployment levels rose to double-figure rates. Also, there appeared to be a significant correlation between war and people's mental health considering changes in suicide rates, implying that war can indeed negatively affect people's state of mind.

\section{Investigating Water Quality and Taxes Paid in Canadian Provinces using Big Data}

\author{
Ege Selcuk, Edgar Lui, Alex Csikasz, Chris Ojo \\ Earl Haig Secondary School
}

This paper analyzes water purity with respect to the amount of taxes paid in that area, within Canada. The purpose of this study was to find the correlation between the taxes paid and the quality of water in a province. We used data sets of waters in rivers and lakes within each province and compared it to data of taxes paid by the citizens of those provinces. This study was performed with the intent of discovering if the government treated water differently based on bias due to taxes. It is common knowledge that contaminated water can be responsible for the outbreak of harmful diseases. If there were a connection between taxes and water purity, it would be detrimental for people in less fortunate areas and would ruin the image of the government. This would mean that the government is restricting a basic human necessity due to income. Using Microsoft Excel and SAS to create graphs and tables, we found that there is no correlation between water treatment and taxes paid across Canadian provinces.

\section{The Role of Public Sentiment from Twitter as a Regulator of Publicly Traded Companies on the Stock Market}

Jake Chua, Herman Liao, Yufei Quan

Earl Haig Secondary School

This paper investigates the relationship between public sentiment by Twitter users regarding the environmental awareness and economic profit of a company. Specifically, the relationship between Twitter sentiments and stock price 
was examined. Public investors and shareholders play a large part in influencing financial markets. Companies can raise money by selling equities to these public investors. If the public believes a firm has the potential to grow, the demand for shares in that company will increase. Firms must maintain a high standard of business to preserve or even improve their share price. As a result, firms must be more transparent and socially responsible in order to maintain the business's reputation.

To measure the degree of public sentiment regarding a company, Tweepy and Alpha Vantage were used to collect tweets and download stock data, respectively. TextBlob, a natural language processor, was used to calculate and analyze the polarity of the tweet; that is, how positive or negative the sentiment is. Python's data management library, Matplotlib, was utilized to plot the stock data and Twitter sentiment.

This analysis was conducted over certain keywords and indexes corresponding to those keywords. The results of this paper confirmed that there is a correlation between public sentiment and stock prices.

\section{Determining Short-Term and Long-Term Solutions for Ocean Acidification}

\section{Chiranjeev Beniwal, Aryan Thatte, Jaden Watson, Yoen Zhang}

\section{Erindale Secondary School}

Faced with the prospect of increasing ocean acidification and subsequent devastation of marine fauna and coastal economies due to carbon dioxide emissions, a strategy for taking carbon dioxide out of the atmosphere is needed. Using trees for carbon sequestration has long been advocated, and by analyzing the effect of forest cover relative to emissions on carbon dioxide concentrations in the atmosphere, we found that having more forest cover relative to emissions strongly correlates with lowered atmospheric carbon dioxide levels. This offers a strong impetus for the mass planting of trees in order to sequester atmospheric carbon dioxide.

\section{The Impacts of Climate Change on Agriculture}

\section{Joshua Lakdawala, Yash Jagirdar}

\section{Erindale Secondary School}

The objective of this study is to examine and investigate the relation between climate change and its effect on water and agriculture. Utilising emission, climate, and water quality data sets from government organizations and written publications, we were able to analyze and visualize relevant data using SAS Studio and Microsoft Excel; which supported the hypothesis that global climate change results in a negative impact on agriculture. By collecting this data, we were able to create visuals to back up our hypothesis. Through the use of the data, it was found that climate change, caused predominantly by carbon dioxide emissions, increases the amount of floods and ice melted, as well as negatively impacting the quality of water. Furthermore, these events create a disruption in agricultural processes and food production, which can lead to malnutrition, starvation, and economic turmoil. In order to solve this, strong collaboration between other countries must begin, goals must be set and followed, and protocols must be regulated. This is clearly a pressing issue, and is a problem that future research can focus on.

\section{Correlation between Climate Change and Fish Landings}

\section{Amos You, David Zhang}

Fremont High School

Living marine resources continue to be at risk from the effects of climate change on the ocean. Nations that are heavily dependent on marine life must research ways into analyzing the effects of climate change on their fisheries in order to facilitate ocean conservation efforts and public policies changes for the purposes of protecting these precious resources. In this study, sea surface temperature and mean sea level are examined as potential variables for understanding trends between ocean climate and fish landings. From this research, it can be concluded that mean sea level rise may have a correlation with fish landings, although there is no conclusion as to whether surface sea temperature has a correlation with fish landings. 


\section{The Effect of Temperature on the Population of Calanus Marshallae Zooplankton in the Gulf of Alaska}

\author{
Vikram Arora, Darian Ellis, Andrew Kang \\ Hillfield Strathallan College
}

The climate of the world has been changing. Sea surface temperatures have risen, affecting marine life. Temperature can have a significant effect on zooplankton since they are poikilo-thermic animals. Zooplankton are vital to the marine ecosystem, as they allow energy to be passed from the primary producers to consumers at higher trophic levels. This study aimed to determine the effect that climate change has on Callanus marshallae, which are a species of zooplankton. This was done by using data that was collected over several years in the Gulf of Alaska. The trends of the abundance and biomass of $\mathrm{C}$. marshallae were examined as well as the temperature of the air. The data was collected from a small data-dense boundary of $59.25-59.87 \mathrm{~N}, 148.87-149.480$ W. The data was filtered further by using samples collected within 25 meters of the depth range. This significantly reduced the likelihood of inconsistencies in this study. The correlation between the year and the abundance of $\mathrm{C}$. marshallae was visualized using histograms, linear regression models and a scatter plot. It was seen in the results that the zooplankton are most abundant in May, which is likely due to phytoplankton blooms. The regression that best fits the data showed that the abundance of C. marshallae was currently decreasing, although the data could not be extrapolated very far into the future. From the data that was analyzed, it can be concluded that climate change impacts $\mathrm{C}$. marshallae decreasing their abundance and mass. This is ecologically significant and may have an enormous impact on marine life. In conclusion, the abundance of C. marshallae was much lower in 2004 than it was in the previous years, demonstrating that in the future, the abundance of $\mathrm{C}$. marshallae will likely continue to decrease.

\section{Investigating the Correlation between Hydroelectric Generation and Climate Change using Data}

\section{Daniel Yan, Zuoxi Luo, Nyah Kuzmicka, James Tang} Hillfield Strathallan College

This paper analyzes the factors of climate change that affects the hydroelectric power output in Canada with data sources online. The purpose of this research is to investigate whether climate change affects the production of hydroelectric power and determine the correlation between the changing climate and power output overtime. With the results, we find that climate change is indeed affecting the hydroelectric output, as temperatures get warmer, the electricity generated does decrease. We also take a quick look at ways to minimise the ways that climate change affects the hydroelectric output.

\section{Impact of Agriculture on Groundwater Availability and Quality in Ontario}

Lukas Bolsinger, ${ }^{\dagger}$ Simon John ${ }^{\ddagger}$

${ }^{\dagger}$ Humberside $\mathrm{Cl}$

*Harbord Cl

This paper investigates the impact of agriculture on groundwater availability and quality in Ontario. In this paper, we narrowly define agriculture as farms with irrigated crops that draw water from wells. The goal of this paper is to determine if irrigation farming practices in our current ecological environment in Ontario reduce water levels in wells, and pollute groundwater supplies. It was concluded that agriculture is not reducing water supply or deteriorating water quality in Ontario.

\section{The Effect of Climate Change on Harmful Algal Blooms in Canadian Water Bodies}

Signe Hoel and Lauren Yoshida

Lawrence Park Collegiate Institute

This study focuses on the global issue of excess algae growth and the negative impacts it has on surrounding 
ecosystems and communities. Canadian lakes are frequent subjects to the detrimental effects of harmful algal blooms and will be the main focus of this paper. In particular, Lake Winnipeg is considered to be one of the most eutrophic large lakes in the world; the over-abundance of nutrients in the water body causing an increase in potentially toxic algal blooms. These blooms harm the lake's ecosystem, threaten the fishery, and reduce the enjoyment of the lake.

There are many factors that may lead to an influx of algal blooms, ranging from the depth of the water body, the volume of inflow coming from tributaries, and an excess amount of nutrients entering it. Although proven to be mainly due to growing amounts of agricultural run-off, there may be, however, other components that cause the frequency and intensity of harmful algal bloom to increase. This paper will discuss the correlation between climate change and harmful algal blooms in Lake Winnipeg and other Canadian water bodies, namely due to changes in precipitation, water temperature and $\mathrm{CO} 2$ levels. Using tools such as python and tableau, the causes and consequences of excess algal growth will be investigated and possible solutions based on findings will be discussed.

\section{Availability of Drinking Water and Climate Change}

\section{Jonathan Sosiak}

\section{Northstar Academy Laval}

The availability of drinking water is not an issue in some parts of the world such as Canada or the United States. However, it is a major issue for countries in Asia ,Mexico, and Australia where drinking water has become a necessary commodity. In this paper, climate change will be discussed and how it impacts the availability of freshwater and what are some possible ways to mitigate a possible solution so that each person has access to potable water.

\section{How the Effects of Clouds are Delaying Arctic Freeze}

Juan Razon, Olivia Findlay, Ariana Blackwood, Camilla Faehndrich

Our Lady of The Snows Catholic Academy
A major climate issue in today's environment is the melting of sea ice in the Arctic. Though people are aware that average global temperatures are increasing, the explanation as to why climate change is accelerating so rapidly deserves further investigation. We believe that this accelerated melting is, in part, affected by the correlation between low and mid level cloud formations in the atmosphere and its albedo effect on sea ice. Clouds are known to warm the Earth's surface due to their high albedo effect reflecting heat back down towards earth. While they also reflect a fraction of the sun's rays, the heat within the earth is recycled back downward due to the clouds causing a decrease in sea ice concentration. Our research has shown a correlation between the amount of low and mid level clouds and the ice concentration in the Arctic. When the ice concentration is low, it is found that the lower level clouds are dispersed more than the mid level clouds causing the reflectivity from the mid level clouds to have a greater impact on the Arctic's surface. While global temperatures keep increasing, the rate of evaporation increases, therefore creating more clouds to trap in further heat, accelerating the rate at which Arctic ice is melting. This information can be used to further understand the rate of change in Arctic sea ice.

\section{Canada's Impact on Water Quality and Weather Patterns Internationally through its Contribution to Climate Change}

Seth Perez, Alison Stanley, Ruby Baty

Our Lady of the Snows Catholic Academy

Canada's waste and incerations has steadily increased. This journal article explains how Canada's waste pollution affects water quality as seen in the Churchill River, and international weather patterns in places such as Bangladesh. We have chosen to focus on this topic due to its implications on quality of life, not only in Canada, but globally, as well as its relevance to the current climate crisis. We used Python and the data analysis program Pandas to manipulate our data. The implications of this data are to further the awareness of Canada's public on the country's international impacts. 


\section{An Analysis of the Effects of Nuclear Power Plants on Stream Water Quality}

\section{Mustafa Emre Basaran, Daniel Jiang, Yagmur Ozturk}

Pickering College

Our research aims to uncover Ontario's three nuclear power plants' influence on stream water quality by analyzing the $\mathbf{2 0 1 6}$ river water quality data published on data.ontario. ca. We calculate the annual averages of the parameters featured in the dataset for each testing site, and plot this information on a set of graphs where the horizontal and vertical coordinates of a point represent the corresponding station's geographical coordinates and its shade represents the magnitude of the annual average for the inspected parameter associated with said station in the context of other data points. We also include the locations of Ontario's nuclear power plants on our graphs in the form of red-coloured dots, and utilize the graphs we produce to study the effects of nuclear power plants on the province's rivers. We find that the plants have minimal to no influence on all featured parameters, while other human activities such as farming and mining cause substantial deviations in the annual averages of nearby stations. Therefore, we conclude that the nuclear plants' impact on water pollution is negligible in comparison to other sources, and that minimizing such sources' impact on the environment should take priority in future planning.

\section{Havoc Below Water: The Detrimental Impacts of Rising pH Levels in Farming Practices and Runoff, Resulting in Unstable Living Conditions for Marine Species}

\section{Cynthia Lim, Palak Agarwal, Shreyas Suri, Vivek Bhardwaj}

\section{Port Credit Secondary School}

The agricultural sector in Canada has demonstrated pivotal importance to both the economic and environmental success of the country. With over $6.78 \%$ of the physical landmass currently utilized, the industry plays a vital role in preserving the environment and its rich biodiversity. To match a globally rising demand for agricultural produce, combined with climate change influences, the farming industry has continually increased the usage of fertilizers over the last 25 years. According to the Food and Agriculture Organization (FAO) of the United Nations, nitrogen-based fertilizers are one of the most commonly used across North America while having the most detrimental impact on marine environments. The widespread usage of nitrogen fertilizers has led to unsustainable nutrient runoff that has made its way into freshwater sources, such as rivers, lakes and streams. In 2014, the Government of Ontario's Water Quality Index Report reported a consistent increase in nitrogen levels within Lake Erie since 1990 as a result of nutrient runoff. Moreover, higher nitrogen levels have been associated with higher levels of algal blooms and a lower $\mathrm{PH}$, resulting in everincreasing acidic waters. The report indicated 8 hotspots in Lake Erie where the Water Quality Index was deemed poor, falling between $0-44$ on the index. The purpose of our study, therefore, was to evaluate the impacts of climate change, caused by nutrient runoff of nitrogen originating from farming fertilizer, on freshwater acidification and its influence on marine and terrestrial species. We evaluated data sets from the Ontario's Water Quality Index Report as well as open-source datasets examining biodiversity in Lake Erie over time. The data sets were correlated using linear regression analysis, and an exponential model to allow for extrapolation of the data, showing a weak moderate correlation coefficient. The model can allow the prediction of future trends, and thus, allow governments to take steps into mitigating negative consequences.

\section{An Investigation into the Effect of Climate Change on the Frequency of Flooding}

\section{Faiz Hanafi, ${ }^{\dagger}$ Nishan Soni, ${ }^{\ddagger}$ Ammar Vora, ${ }^{\ddagger}$ Vishwanath Wimalasena ${ }^{\ddagger}$ \\ ${ }^{\dagger}$ Robert Thirsk High School \\ ‡Sir Winston Churchill High School}

This is a scholarly investigation into the effects that global climate change has on the frequency of regional flooding in Ontario, as well as looking into the economic consequences incited by said flooding. This analysis is important to the study of climatology as relevant data must be collected in order to explore the impact of the natural world on real populations. As a result, appropriate and reliable methodologies should 
be used for the investigation. We used climatic, economic, and flood data from locations ranging across Ontario, and utilized powerful analytical tools such as Python 3, Microsoft Excel, and Jupyter. From these, intriguing and insightful results were gathered, which were not altogether the most expected outcomes. When plotting the frequency of floods as a function of time, the data portrayed an acute increase in the number of floods over time. This correlates to the proportional increase in temperature over the past century. What was unexpected however, was the correlation (or rather the lack of correlation) between economic damage and frequency of floods. Our proposed hypothesis predicted that economic damages would increase over time, the data clearly shows that no significant pattern can be interpreted as the years have gone on, and as flooding rates have inflated. The 'Discussion' and 'Results' section of this paper examines these facts in detail. To conclude this abstract, the future implications of this research should be examined. Namely, as more time passes, the number of floods in Ontario can only be expected to increase, but some regional economies will not be affected by the increased natural disastoral activity.

\section{Determining the Effects of Sea Level Rise on Rice Production in Vietnam}

\section{Ivy Guo, Nikki Guo}

\section{Sir John A. Macdonald Collegiate Institute}

The purpose of this study is to determine the impact of rising sea level on rice cultivation in Vietnam. Vietnam is one of the world's largest producers of rice. Being a low-lying country, Vietnam is vulnerable to the increasing water levels of its surrounding bodies of sea water.

The outcome of the rice crop heavily depends on using the correct procedure and an appropriate environment. Hence, sea level rise poses a risk to the rice cultivation industry since it harms

the rice paddies. Consumed globally, rice is an essential good for nourishment, its by-products, and as a source of income. This study was based on Southern Vietnam, specifically the area of the Mekong River Delta, as it is located in proximity to the South China Sea. Its high production of rice gives it the name, the "rice bowl" of Vietnam. Open source data on various aspects of rice production in Southern Vietnam, and data on sea level were analysed using Python
3 and Microsoft Excel to determine trends and correlations. Findings concluded that there was a correlation between sea level rise and the decrease of rice production, as well as an increase of damaged rice paddy overtime. Specifically, during the winter growing season, from 2014 to 2017, there was a $63 \%$ drop in the production of rice in the province of Kien Giang, correlating to the higher water levels at a water station located nearby. There was an increase of 470849 ha of damaged paddy area in the Mekong River Delta Region from 2015 to 2016 . Potential uses of this study may be researching the effect of seawater on nutritional content of rice, soil fertility, as well as further research into the adaptation of the agricultural industry across all crops.

\section{Factors Affecting Phytoplankton Populations and Possible Solutions Towards Preserving} Them

\section{Lai Amy, Liwongan Keanu, Trivedi Ananya \\ Sir Winston Churchill High School}

Phytoplanktons are microscopic, photosynthetic algae that form the base of the marine food web. In this investigation, trends that reflected the phytoplankton populations were observed, along with the environmental factors affecting them. Recent experiments performed in oceanographic laboratories using small algal samples have shown that phytoplanktons have a relatively higher growth rate under warmer temperatures; however, with increasing global temperatures, there has been a worldwide decline in phytoplankton populations in the oceans. With the help of this investigation, it was found that the increasing sea surface temperatures (SSTs) are a possible reason for the population decline. Water temperature is a key factor affecting phytoplankton bloom dynamics in waters, which in turn has the ability to change the entire food web and ecosystem services. Rapidly increasing surface temperatures deems ineffective in acting as the optimum living conditions for phytoplanktons, since the nutrients required by the phytoplanktons in order to thrive usually sink to the bottom of the ocean, thus depriving them of their nutrition. This phenomenon is known as thermal stratification. If there are not enough phytoplanktons to convert the atmospheric $\mathrm{CO} 2$ into breathable $\mathrm{O} 2$, the already high $\mathrm{CO} 2$ levels will skyrocket. Being a significant greenhouse gas, $\mathrm{CO} 2$ has undeniable after 
effects in the atmosphere such as increased $\mathrm{pH}$ levels of oceans, rapidly increasing SSTs, and increased trapping of the sun's heat. In the investigation, we will suggest ways of how to replenish the ocean nutrients in order to cope up with the thermal stratification caused due to warmer SSTs.

\section{Understanding the Effect of Climate Change on River Flow in the North Saskatchewan River}

Shrinjay Mukherjee, Sunny Zhou, Max Zhong, Abhigyan Garg

\section{Sir Winston Churchill High School}

Rivers are an integral part of urban civilization, and most of the world lives near one, yet the 2013 Floods in Southern Alberta reflect a larger worldwide pattern of unpredictable flows and flooding. By analyzing river flow, the volume of water passing a given point per unit time, and weather data for the North Saskatchewan River at Edmonton using Python, insights into the relationship between climate change and river flow can be revealed. An analysis of the Canadian Disaster Database reveals that while floods are less common in the 2010s, compared to the 1990s and 1970s, they are far more damaging, with higher costs, fatalities and evacuations. Statistical analysis of mean river flow, and its correlation with snowfall, summer precipitation and glacial mass balance reveal a decrease in snowfall over time. This leads to reduced glacial mass balance over time, as less snow accumulates during the winter, thus compounding the effects of glacial retreat. The result is reduced mean river flow, but an increase in the difference between maximum and minimum river flow in a given year, due to earlier and faster snow melt during spring. This suggests that the effects of climate change are reduced flow, but more unpredictable flow, which carries the threat of both flooding during peak flow and water shortage in situations of increased demand.

\section{On the Correlation between Freshwater Availability and Peacefulness}

\section{Andrew Chen, Louis Sun}

\section{St. Augustine Catholic High School}

The objective of this study was to investigate a possible correlation between water stress and peacefulness in the world. To accomplish this, we used both Tableau and Microsoft Excel to organize, visualize, and analyze both the Aqueduct Index and the Global Peace Index. The Aqueduct Index measures water stress, while the Global Peace Index measures world peace. We plotted the Aqueduct Index data and the Global Peace Index data on a scatter plot first globally and then by region. We found no correlation between the two indices globally due to there being too many non-water related factors affecting the Global Peace Index. However, when comparing countries with similar socioeconomic and geographic circumstances, we found strong positive correlations between a lower peace level and water stress.

\section{Correlation between Industry Air Pollutant Emissions and $\mathrm{pH}$ of Precipitation in the US: A Predictive Analysis of Industrial Impact on Precipitation Acidity}

Bishneet Singh, Brennan Cowley Adam, Lindy Zhai

Strathcona-Tweedsmuir School

When one thinks of long term sustainability, one of the first things that comes to mind is improving water quality. It is no secret that much of the world is without safe drinking water; however, many industrial countries also face a serious water quality problem. With the increased industrialization, there is no doubt that air pollutants have affected water quality. Specifically, these emissions which are being pumped into the air are affecting humans through the formation of acid rain which wreaks havoc on lakes, rivers, farmland, and other ecosystems.

This study aims to find correlations between different emissions from certain industries, such as cement factories and refineries, and the $\mathrm{pH}$ of the precipitation in the United States from 1990 to 2005. Datasets from the US government detail the emissions of carbon dioxide (CO2), oxides of nitrogen (NOx) and sulfur dioxide (SO2, as an example of SOx) as well as the $\mathrm{pH}$ of precipitation across the country was processed in order to find correlations and trends between the three variables. Using Python and its data analysis libraries, graphs were generated to compare each of these variables and find a strong relationship. Not only did this study find a strong trend between NOx emissions, SOx emissions, and the $\mathrm{pH}$ of rainwater, it also explores the impact of different industries on the $\mathrm{pH}$ of rainwater through predictive analysis. A random 
forest model was trained to predict the amount of NOx, SOx, and $\mathrm{CO} 2$ for any number of industrial facilities within a city. This way, it became possible to predict optimal city layouts and ensure long term sustainability.

\section{A Review of the Association of Floods and Precipitation with Homelessness in Texas from 2007 to 2016}

\section{Brian Hsiao, Kelly Hu, Olivia Chen \\ Torrey Pines High School}

In Texas, floods and hurricanes are very common, leaving a part of the population homeless. For instance, in 2008, Hurricane Ike left 42,000 people without homes and 37 dead. One of the causes of floods is a high rate of precipitation. Global warming increases the chances of flooding when temperature rises. When carbon dioxide, a heat-trapping pollutant, is released into the atmosphere, moisture is kept in the air. This results in more rainfall. In the process of researching the correlation of these two factors, Statistical Analysis tools such as Jupyter Notebook and Python were used to create a linear regression graph. To help prevent floods, companies should make products that are durable, efficient and waterproof material and are strong enough to protect houses. It is also recommended that the government or organizations provide sufficient shelter for those who have lost their homes.

\section{The Effects of Climate Change on Waterborne Illnesses}

\section{Riya Kumar, Elizabeth Zhu, Amsal Gilani, Ayleen Farnood}

\section{University of Toronto Schools}

This study analyzes the relationship between the warming of the oceans, as a result of climate change, and the spread of waterborne illnesses. The correlations between increased flooding and waterborne illnesses as well as proximity to water and waterborne illnesses were examined to determine if such a relationship exists. Data from the Journal of Geomatics, Natural Hazards and Risks, the National Oceanic and Atmospheric Administration, the US Environmental Protection Agency, and Centres for Disease Control and
Prevention were used to investigate the relationship. Furthermore, for data analysis and visualization, the software Tableau was utilised for the creation of all graphs while Microsoft Excel was used for data cleaning, organization, and analysis as well.

This paper concludes that there is a correlation between climate change and the number of outbreaks of waterborne illnesses. In particular, the increased precipitation due to climate change has resulted in more floods occurring each year. Due to the warmer temperature of the water, these floods act as optimal breeding grounds for waterborne illnesses, which are able to then spread further in-land. As a result, it was found that coastal regions are especially prone to experiencing outbreaks due to their proximity to water and higher flood risk.

\section{Investigating the Impacts of Ocean Temperature and Salinity Change on Agriculture}

\section{Zahra Mustin, Mathew Lane, Veronika Berbeka}

\section{University of Toronto Schools}

Since the 1950s there have been many observed impacts on the climate over all continents and oceans. With the IPCC almost certain that humans are the primary cause of the current global changes, it is crucial to act before more human activities disrupt the climate, thereby heightening the risks of severe, pervasive and irreversible impacts for people and ecosystems. Ocean warming dominates the increase in energy stored in the climate system, accounting for more than $90 \%$ of the energy accumulated between 1971 and 2010 (high confidence), with only about $1 \%$ stored in the atmosphere. Because of the high oceanic uptake of $\mathrm{CO}$, there has been a significant increase in ocean acidity which has had negative global impacts on the agricultural industry. In this report we will be examining different solutions to counteract these issues. 


\section{The Effects of Melting Glaciers on Fish Biodiversity}

Siddarth Dagar, Jerry Wang, Ryan Alizadeh, William Szeto

\section{University of Toronto Schools}

The purpose of this study was to examine data on fish population shifts and ocean warming in the Davis Strait and Baffin Bay region, and consider how these shifts may affect Inuit communities. We examined data from 1950 to 2010 on fish sightings as well as trends in warming and decreasing salinity due to melting glaciers in that region. Specifically, we conducted generational analysis of various fish species alongside heat maps of fish spottings which were used to determine population migration trends for certain species. We found a recent shift in migration patterns for several species of fish which may be correlated with the previously established ocean warming. This shift was observed in the species Macrouidae, Myctophidae, Phycidae, Zoarcidae, and Salmonidae. The migration of the Salmonidae is especially consequential due to the dependence of Inuit peoples on salmonidae for their food during certain parts of the year. Assuming that this link is causal, and that feedback mechanisms for glacial melting will only accelerate warming, we anticipate that this effect has the potential to upset traditional ways of life for Inuit communities in the region.

\section{Predicting Hurricane Frequency and Intensity Using Ocean Data and Boosting Algorithms}

\section{Alex Zhuang, Jason Xiong, Baker Jackson, Nathan Kim}

University of Toronto Schools

Recent years mark some of the most destructive hurricanes ever recorded in the Atlantic, causing record-breaking levels of damage to coastal communities and the environment. The increase in hurricane intensity has been hypothesized to be linked to anthropogenic ocean warming, highlighting the dangers of accelerating climate change. In this paper, we investigate the proposed relationship using a two-part analysis of over 40 years of oceanographic data and hurricane records in the North Atlantic ocean. Using recent advances in machine learning and boosting algorithms, we aim to make sense of the large amounts of data used in climate stewardship. First, we compare the overall trend in surface temperatures (SST), sea-level pressures and wind shear in the North Atlantic since 1980 with corresponding trends in hurricane intensity as measured by the Saffir-Simpson Hurricane Wind Scale (SSHWS). Second, we partition the measurements by geographic location and create features based on the monthly average measurement of each variable (SST, wind shear, pressure). Using these features as input, we trained two gradient boosting models to predict the monthly average frequency and intensity respectively of a storm in the North Atlantic. Through our analysis of sea surface temperatures, and measures of hurricane intensity and frequency, we determined the predicted increase over time with the current rate of climate change. The investigation of the relationship between wind speed and ocean warming indicates that rising temperatures may be a key factor in increasing hurricane intensity, consistent with theoretical arguments in literature. We determined the most important location-based factors to predicting the intensity of North Atlantic storms and obtain an accuracy of $91.35 \%$ for the prediction of storms storm intensity. Creating awareness surrounding the impacts of climate change will be critical in taking climate action, and understanding its wide-ranging impacts. With this analysis, we urge governments and NGOs to take action in reducing global temperatures in order to prevent the previously unprecedented consequences of climate change.

\section{Investigating the Effects of Climate Change on Agricultural Yields Through Ocean Salinity Analysis}

\section{Halley Halim, Emily Wan, Jenny Wu}

\section{University of Toronto Schools}

The purpose of this paper is to determine whether there is a relation between climate change and agricultural yield, and if so, what that relation is. We used both Canadian and international climate, agricultural, and ocean data sets. We graphed the data using Python, Jupyter Notebook, and MatPlotLib. Besides raw data sets, this report also includes worldwide maps from NASA displaying salinity and sea level information. After analyzing the results, it was concluded 
that there was a correlation between climate change and agricultural yields. We suspect that climate change causes sea levels and sea salinity to increase, which leads to an increase in soil salinity. Ultimately, salt-affected soils reduce agricultural yields. The hypothesis that there is a strong negative relation between sea level and agricultural yields is supported by the correlation coefficient between these two factors: $-85 \%$. Reduced agricultural production is one of several major issues caused by climate change, and it is a worthwhile topic for further research.

\section{The Effects of Climate Change and Rising Sea Levels on Migration Patterns}

\section{David Tang, Jacky He, Bill Hu, William Li \\ University of Toronto Schools}

Climate change and its potential effects have been known to the public for many years. However, it is also crucial to assess the degree to which such awareness affect people's behaviour. One of the most significant effects of climate change that our group decided to focus on is rising sea levels. We hypothesize that this would lead to the migration to inland cities due to increased maintenance costs for real estate in coastal cities. Therefore, an effective proxy for the effects of climate change on people's actions would be the change in the rate of growth of coastal cities in comparison to that of inland cities. We obtain the statistics on population over time using available UN data of 1860 cities from over 100 different countries and all 6 major continents. In addition, statistics on the distance to coast for each of those cities are acquired through a KBGeo API given the longitude and latitude of each city. We organized the cities into 3 categories of small, medium, and large. The results indicate a slight positive correlation between distance to coast and change in the rate of growth of cities for all cities of all sizes, but below the $5 \%$ significance level. The implication is that although there is a very small minority $(\approx 2.5 \%)$ of people who are both aware of rising sea levels and take personal actions towards avoiding its harmful effects, many might not believe in climate change or care about its long term consequences.

\section{Investigating the Effects of Climate Change on Atlantic Ocean Hurricanes}

\section{John Zhang, Karan Manku, Simha Kalimipalli}

Waterloo Collegiate Institute

Hurricanes have been increasing over time in both number and scale. Given that the threats from climate change only will exacerbate hurricanes as the oceans warms, this study aims to determine the effects of climate change on hurricanes occurring in the Atlantic Ocean by quantifying correlations between ocean climate, and hurricane frequency and hurricane season activity. This was done by measuring the relationships between ocean heat content, and hurricane strength, measured using Accumulated Cyclone Energy (ACE), damages on coastal cities in terms of monetary value, and frequency. The data analysis was performed using Python 3.7 and Microsoft Excel.

It was found that there is a moderate, positive correlation between Ocean Heat Content and Accumulated Cyclone Energy, causing hurricanes to get more dangerous and inflict more devastation as the effects of climate change take place. This identified relationship will help predict future hurricane trends using projected ocean temperature changes. As a consequence of the analysis conducted, this study strongly recommends a proactive stance against warming oceans and climate change. Failure to act in such a manner could endanger the lives of many coastal inhabitants to increasingly dangerous and frequent hurricanes.

\section{Analysing the Effect of Changing Water Habitats and Populations of Phytoplankton}

\section{Susan Fountain, Harsh Patel, Anya Pedersen \\ Webber Academy}

This goal of this paper was to compare phytoplankton populations with various habitat factors, to try and project future blooms of phytoplankton. We chose to analyse whales because they excrete nitrogen in a form that is usable and essential for these organisms to grow. We also took into account changes in water $\mathrm{pH}$ and temperature which affect phytoplankton reproducing rates.

Through analysing populations of phytoplankton, our 
goal was to find determining factors that affect populations of various species. Through the knowledge tha whale feces provide accessible nitrogen to the phytoplankton at the euphotic level of various bodies of water.

Through analysing data online of whale populations and locations from the International Whaling Commission, we were able to compare the populations of whales with location of phytoplankton from COPEPOD databases. We also analysed water $\mathrm{pH}$ levels and temperature to evaluate fluctuations that could also affect phytoplankton populations.

We found that locations of whales and phytoplankton tend to be around coastlines, as well as fluctuations in water $\mathrm{pH}$ is common. Analysing the datasets, we found that whale locations and phytoplankton locations do tend to be around similar areas, yet this could also be due to various coastal aquatic ecosystems, like coral reefs. Through observing the common fluctuations in water $\mathrm{pH}$, it is clear that predicting phytoplankton population cannot be done by analysing one factor. Even though nutrient levels are important for their growth, phytoplankton must have a stable water $\mathrm{pH}$ to reproduce at a growing rate.

\section{Using Global Surface Water and Temperature Data to Identify Key Factors in Water Resource Conservation}

\section{Allan Cao, Alexander Greco, Duomi Ding \\ Westmount Charter School}

The purpose of this study is to investigate the potential relationships between changes in surface water levels and the change in temperature in certain areas around the world. Surface water is a vital resource, as it represents most of the water humans consume, and its conservation is crucial to addressing water scarcity and may also prove a method to combat climate change.

Using data sets from the European Commission's Joint Research Centre and climate analysis by the Copernicus Climate Chance Service, we are able to compare the data using Google Earth Engine to analyze the data. We found that in studied areas near human civilization, surface water levels decreased while temperatures increased. This supports our initial hypothesis that areas of surface water decrease corresponded to areas where the temperature increased.

Our research leads us to believe that while human activity may not be the primary cause of surface water depletion in certain areas, further research is warranted to better advise how surface water should be consumed and conserved both to tackle problems of water scarcity and to take appropriate actions in addressing global climate change.

\section{Ocean Phosphate Pollution - The Relationship between Maritime Phosphate and National Prosperity}

Tony Hu, Andrew Li, Dhananjay Patki, William Zho Westmount Charter School

Phosphate rock reserves are estimated to be depleted in 50 - 100 years, with the point of highest phosphorus production expected to be reached in 2030. Phosphate, the base of many fertilizers, is a non-renewable resource. Ocean phosphate concentration gives a good indication of phosphate use worldwide, where agricultural runoff leads to an increase in ocean phosphate concentration.

This study explores the concentration of phosphate in ocean water, particularly its relationship to the Social Progress Index of nations, with respect to UN Sustainable Development Goals 11 and 12. Phosphate concentration data were collected from the National Oceanic and Atmospheric Administration and compared with factors of social welfare from the 2018 Social Progress Index. Each factor was separately compared to the ocean phosphate concentration data, and a linear regression was performed on each of them.

The results of the linear regressions indicated that countries ranked higher on the Social Progress Index had higher ocean phosphate concentrations within their maritime borders, indicating that more developed nations had, overall, higher levels of phosphate. The results led to the conclusion that countries of higher social wellness contribute more to global phosphate use or have higher amounts of fertilizer runoff, of which the significance to sustainable resource development and environmental protection is invaluable.

\section{El Niño's Effect on Water Quality}

\section{Amisha Gill and Priscilla Chirom}

Westmount Charter School

El Niño is a natural climate recurring phenomenon that 
affects various areas of the world, described as the unusual warming of surface waters around the Pacific Ocean. This study aims to find the correlation between the effects of El Niño on the water quality in our different seas. Analyzing the environmental and some socioeconomic indicators within each country around these bodies of water and the analysing the indicators within each of these bodies of water, comparisons can be drawn between the influence that El Niño has on the bodies of water of the surrounding countries. This is done by applying a linear regression model to all the relationships to determine the factors that appear to correlate El Niño and its negative effects on water quality rates with R-squared determined for each relationship. The purpose of this study is to identify the major consequences that this phenomenon holds on the health of the population and the health of the major water ecosystems, which can further help future policy-making and planning. 